\title{
Surgical anatomy of the tricuspid valve
}

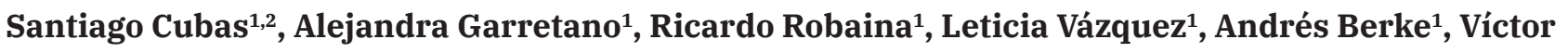 \\ Dayan $^{2}$
}

${ }^{1}$ Department of Anatomy, Faculty of Medicine, University of the Republic of Uruguay, Montevideo, Uruguay

${ }^{2}$ Cardiovascular Center, University of the Republic of Uruguay, Montevideo, Uruguay

\section{SUMMARY}

The aim of this study was to describe danger zones between the tricuspid annulus and the coronary sinus and the right coronary artery to be considered during tricuspid interventions. Methods: 36 hearts from human adult corpses were dissected. We measured the distance between the middle third of the anterosuperior (anterior) leaflet to the right coronary artery (distance 1), between the anteroinferior (anteroposterior) commissure to right coronary artery (distance 2), between the middle third of inferior (posterior) leaflet to the right coronary artery (distance 3) and between the middle third of the septal leaflet to the ostium of the coronary sinus (distance 4). Distances were compared between right and left coronary dominance. The average distance 1 was $5,32 \mathrm{~mm}$ (1-11 $\mathrm{mm})$, the average distance 2 was $3,07 \mathrm{~mm}(0.5-7 \mathrm{~mm})$, the average distance 3 was $2,53 \mathrm{~mm}(0.5-12 \mathrm{~mm})$ and the average distance 4 was $8,55 \mathrm{~mm}$ (2.5-18 mm). 31 hearts had right dominance, 4 left dominance and 1 codominance. We found no statistically significant differences between hearts with right and left coronary dominance at either D1 $(5.26 \pm 2.55 \mathrm{~mm}$ vs $6.62 \pm 1.80 \mathrm{~mm}, \mathrm{p}=0.213)$ or $\mathrm{D} 4(8.55 \pm 3.91$ $\mathrm{mm}$ vs $11.62 \pm 0.95 \mathrm{~mm}, \mathrm{p}=0.064)$. The highest risk area of injuring the right coronary artery corresponds to the posterior annulus (distance 3 ). In hearts with left dominance, tricuspid annulus

Corresponding author:

Santiago Cubas. Luis B. Cavia 2883/001, Montevideo, Uruguay. Phone: +59899981355. E-mail: cubassantiago@hotmail.com has a safer distance to the right coronary artery and coronary sinus and therefore may present a lower risk of right coronary artery involvement in surgical and endovascular procedures.

Key words: Right coronary artery - Tricuspid valve - Tricuspid annulus

\section{INTRODUCTION}

Tricuspid valve (TV) disease can manifest itself in three different ways: stenosis, primary regurgitation, and secondary regurgitation. Secondary tricuspid regurgitation (TR) is the most common tricuspid valve pathology and responds to right ventricular (RV) dysfunction due to pressure or volume overload in the presence of structurally normal leaflets. Most patients who undergo tricuspid valve interventions do so during concomitant mitral or aortic valve intervention or myocardial revascularization (Vassileva et al., 2012).

Although surgery is still the gold standard for tricuspid valve corrective treatment, interventional procedures are currently under way for high-risk patients (Campelo et al., 2017). In order to avoid the inherent risks in these procedures, it is essential to achieve a comprehensive knowledge of the anatomy of the valve and its main relationships, mainly with the

Submitted: September 24, 2021. Accepted: November 11, 2021 https://doi.org/10.52083/QOAI6106 
atrioventricular node (NAV), right coronary artery (RCA) and the ostium of the coronary sinus (CS).

Our aim was to describe zones of proximity (and danger) between the tricuspid annulus and the CS and the RCA in order to consider during tricuspid interventions.

\section{MATERIALS AND METHODS}

\section{Anatomical approach}

The material used to carry out this work was donated under a written consent to the Department of Anatomy.

An observational descriptive anatomical study was performed using 36 hearts from human adult corpses previously fixed in formaldehyde solution. The age of the corpses was in the range from sixtyfive to seventy-five. The donors were patients without cardiac pathology. We excluded from the sample any donors with cardiac pathologies.
The chest was approached through a bilateral para-median lateral thoracotomy, and the cardiopulmonary block was subsequently removed. An inverted "T" pericardiotomy was performed. The heart was released after sectioning of the intrapericardial pulmonary veins, vena cava, and supra-aortic vessels. Once the heart was released, the right atrium was approached through a right cava-cava atriotomy, and the incision was extended parallel to the tricuspid ring. Location and branches of the RCA were identified.

Measurements were taken from the atrial side of the middle third of the anterosuperior (anterior) leaflet, the anteroinferior (anteroposterior) commissure, the middle third of the inferior (posterior) leaflet and the middle third of the septal valve (Fig. 1).

The following distances were recorded: 1) Distance 1 (D1) - shortest distance from the

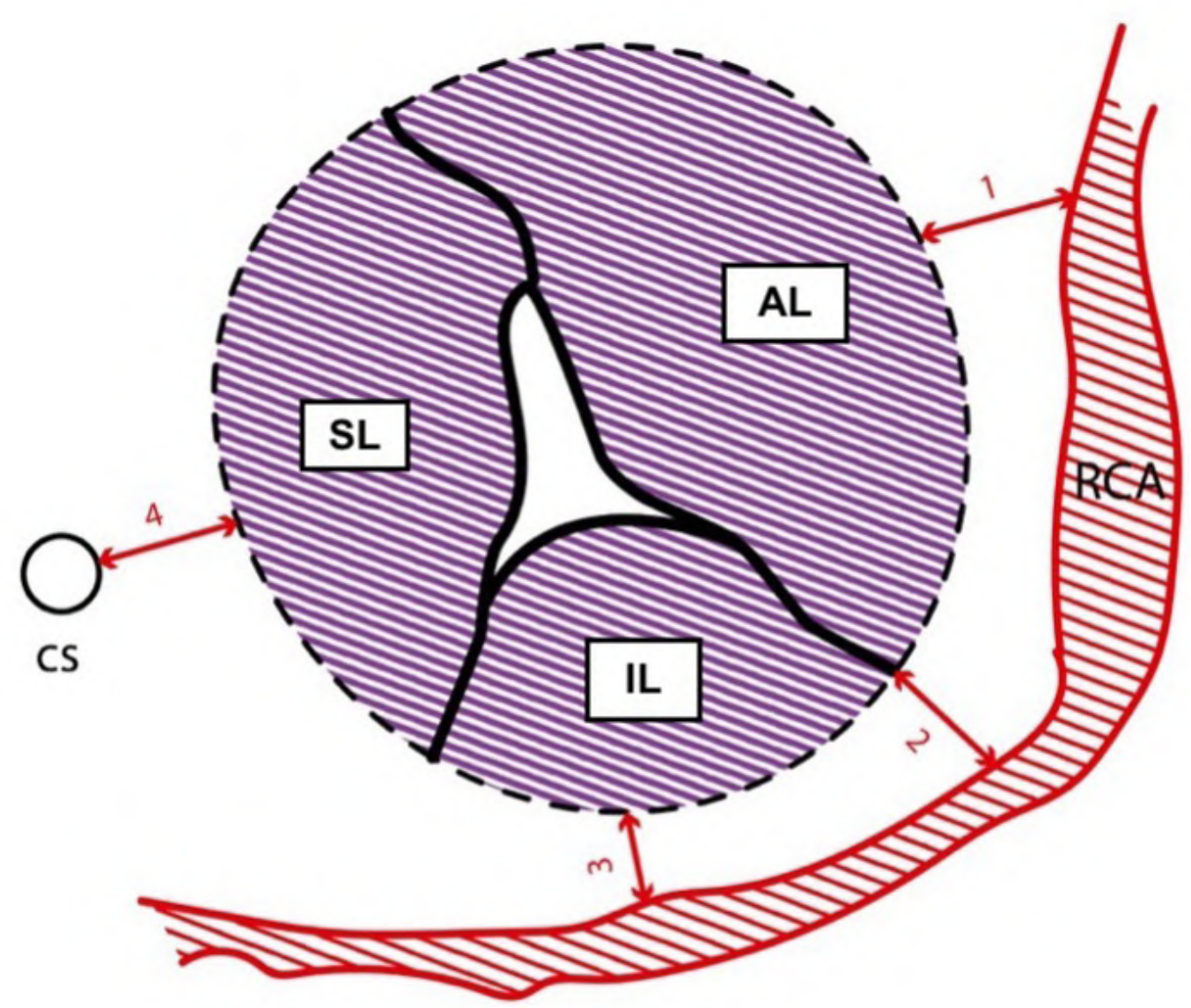

Fig. 1.- Schematic representation of the tricuspid valve (atrial view) in relation with the right coronary artery, and the coronary sinus. SL: Septal Leaflet. AL: Anterosuperior Leaflet. IL: Inferior Leaflet. CS: Coronary Sinus. RCA: Right Coronary Artery. 1: distance 1. 2: distance 2. 3: distance 3. 4: distance 4. 
middle third of the anterosuperior leaflet to the RCA; 2) Distance 2 (D2) - shortest distance from the anteroinferior commissure to the RCA; 3) Distance 3 (D3) - shortest distance from the middle third of the inferior leaflet to the RCA; 4) Distance 4 (D4) - shortest distance from the middle third of the septal leaflet to the ostium of the coronary sinus (Figs. 1, 2 and 3).

Coronary dominance was defined as the coronary artery which gave rise to the posterior descending artery (Knaapen et al., 2013). In hearts with left dominance, it was not possible to take the measurement in relation to the anteroinferior commissure and inferior leaflet (Distance 2 and Distance 3).

Distances were compared in specimens with left and right coronary dominance using MannWhitney U test.

All measurements were made with a numerical millimeter caliper and by the same observer. Continuous variables were expressed as mean, range (minimum-maximum) and standard deviation (SD). Categorical variables as absolute numbers and \%. P-value $<0.05$ was considered significant.

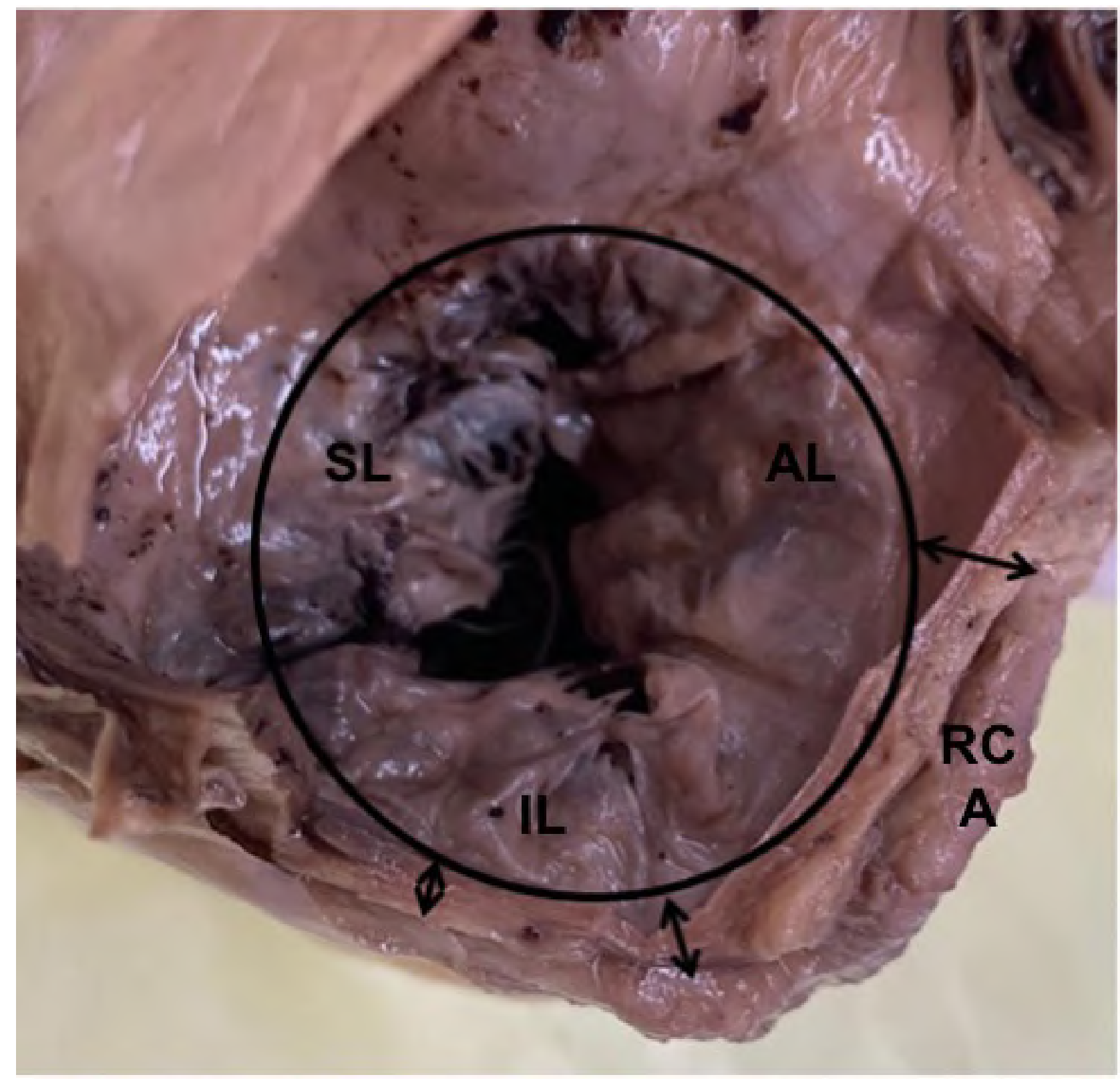

Fig. 2.- Atrial view of the tricuspid valve. SL: Septal Leaflet. AL: Anterosuperior Leaflet. IL: Inferior Leaflet. Arrows indicate the points of measure between the annulus to the right coronary artery. 


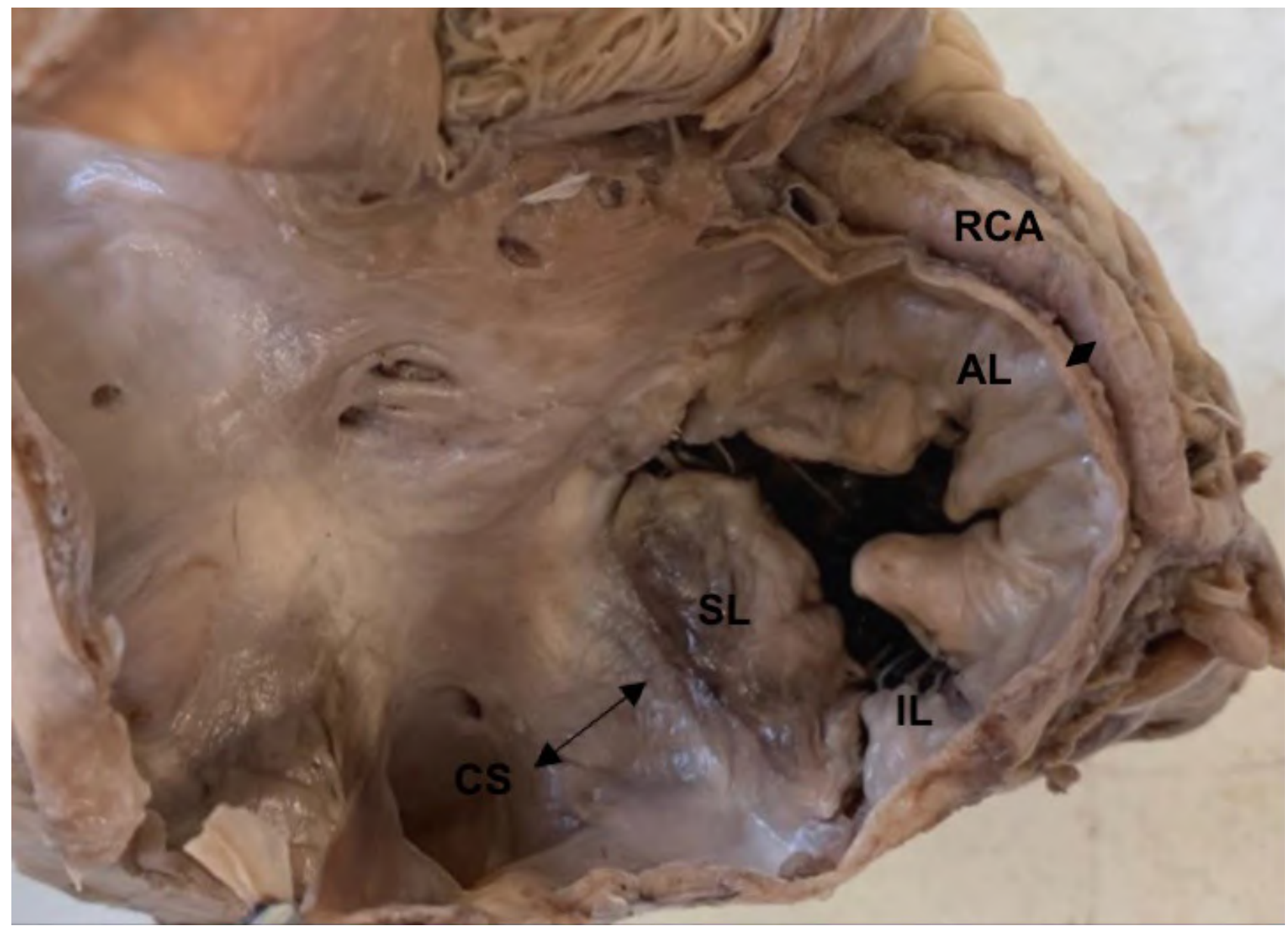

Fig. 3.- Atrial view of the tricuspid valve in cadaveric piece. Pattern of Left dominance. SL: Septal Leaflet. AL: Anterosuperior Leaflet. IL: Inferior Leaflet. CS: Coronary Sinus. RCA: Right Coronary Artery. Arrows indicate the points of measure between the annulus to the Coronary Sinus, and the annulus to Right Coronary Artery.

\section{RESULTS}

Of the 36 hearts, 31 presented right dominance (86.1\%), 4 left dominance (11.1\%) and 1 codominance (2.8\%).

Mean D1 was $5.32 \mathrm{~mm}$ (1-11 mm), D2 was 3.07 $\mathrm{mm}(0.5-7 \mathrm{~mm})$, D3 was $2.53 \mathrm{~mm}(0.5-12 \mathrm{~mm})$ and D4 was $8.81 \mathrm{~mm}(2.5-18 \mathrm{~mm})$ (Table 1$)$.

In hearts with right coronary dominance, mean D1 was $5.26 \mathrm{~mm}(1-11 \mathrm{~mm})$ and standard deviation (SD) was 2.55 , D2 was $3.06 \mathrm{~mm}$ (0.5-7 $\mathrm{mm})$ and SD was 1.66, D3 was $2.53 \mathrm{~mm}(0.5-12$ $\mathrm{mm})$ and SD was 2.26, D4 was $8.55 \mathrm{~mm}(2.5-18$ $\mathrm{mm}$ ) and SD was 3.9 (Fig. 4).

In hearts with left coronary dominance, mean D1 was $6.62 \mathrm{~mm}$ (4-8 $\mathrm{mm}$ ) and SD was 1.80, D2 and D3 was not possible to obtain in this dominance pattern. Mean D4 was $11.62 \mathrm{~mm}(11-13 \mathrm{~mm})$ and SD was 0.95 (Fig. 4).
In the only case of codominance, mean D1 was 2 $\mathrm{mm}$, D2 was $3.5 \mathrm{~mm}$, D3 was not possible to obtain in this dominance pattern. Mean D4 was $5.5 \mathrm{~mm}$.

We found no statistically significant differences between hearts with right and left coronary dominance at either D1 $(5.26 \pm 2.55 \mathrm{~mm}$ vs $6.62 \pm 1.80 \mathrm{~mm}, \mathrm{p}=0.213)$ or $\mathrm{D} 4(8.55 \pm 3.91 \mathrm{~mm}$ vs $11.62 \pm 0.95 \mathrm{~mm}, \mathrm{p}=0.064$ ) (Table 2 ).

\section{DISCUSSION}

Tricuspid regurgitation (TR) is one of the most common manifestations of valvular heart disease (VHD) and may affect $65-85 \%$ of the population.

Primary TR implies pathology of the tricuspid valve (TV) complex and may be of rheumatic, degenerative, congenital, infectious, traumatic, or iatrogenic (usually secondary to pace- maker leads) origin. Secondary (or functional) TR is the most prevalent tricuspid pathology and related to right ventricular (RV) dilatation and/ 
or dysfunction, annular dilatation, and leaflet tethering, which are, in turn, usually secondary to left-sided VHD (especially affecting the mitral valve), atrial fibrillation or pulmonary hypertension (Antunes et al., 2017).

The TV annulus is part of the fibrous skeleton of the heart and has important anatomical relationships with the atrioventricular node, the RCA and with the ostium of the CS. A profound and extensive knowledge of its relations is imperative for anyone intervening on the TV in order to avoid serious complications. Our investigation has shown that the area of greatest risk for injury to the RCA is at the anterior-inferior commissure as well as the middle of the inferior leaflet. Using a clockwise system, with 0 corresponding to half of the anterior annulus, the area of greatest risk for injuring the RCA is the zone between 4 and 6 o'clock (Figs. 5 and 6). This risk might be higher for patients with right coronary dominance.

The relationship of the RCA with the annulus acquires importance for the surgical and interventional approach of the TV. The RCA runs through the right atrioventricular sulcus and gives rise to the posterior descending artery in 85-90\% of cases (Knaapen et al., 2013) (right dominance). It has been described that, in right dominance, the RCA has closer relationship with the tricuspid annulus but there is limited information regarding the minimum safety distance (Dahou et al., 2019).

Table 1. Distance between the tricuspid annulus and the right coronary artery and coronary sinus (n=31).

\begin{tabular}{|l|l|l|l|l|l|}
\hline & N & Mean & Minimum & Maximum & SD \\
\hline Distance 1 $(\mathrm{mm})$ & 36 & 5,32 & 1,00 & 11,00 & 2,52 \\
\hline Distance 2 $(\mathrm{mm})$ & 32 & 3,07 &, 50 & 7,00 & 1,64 \\
\hline Distance 3 $(\mathrm{mm})$ & 31 & 2,53 &, 50 & 12,00 & 2,26 \\
\hline Distance 4 $(\mathrm{mm})$ & 36 & 8,81 & 2,50 & 18,00 & 3,80 \\
\hline
\end{tabular}

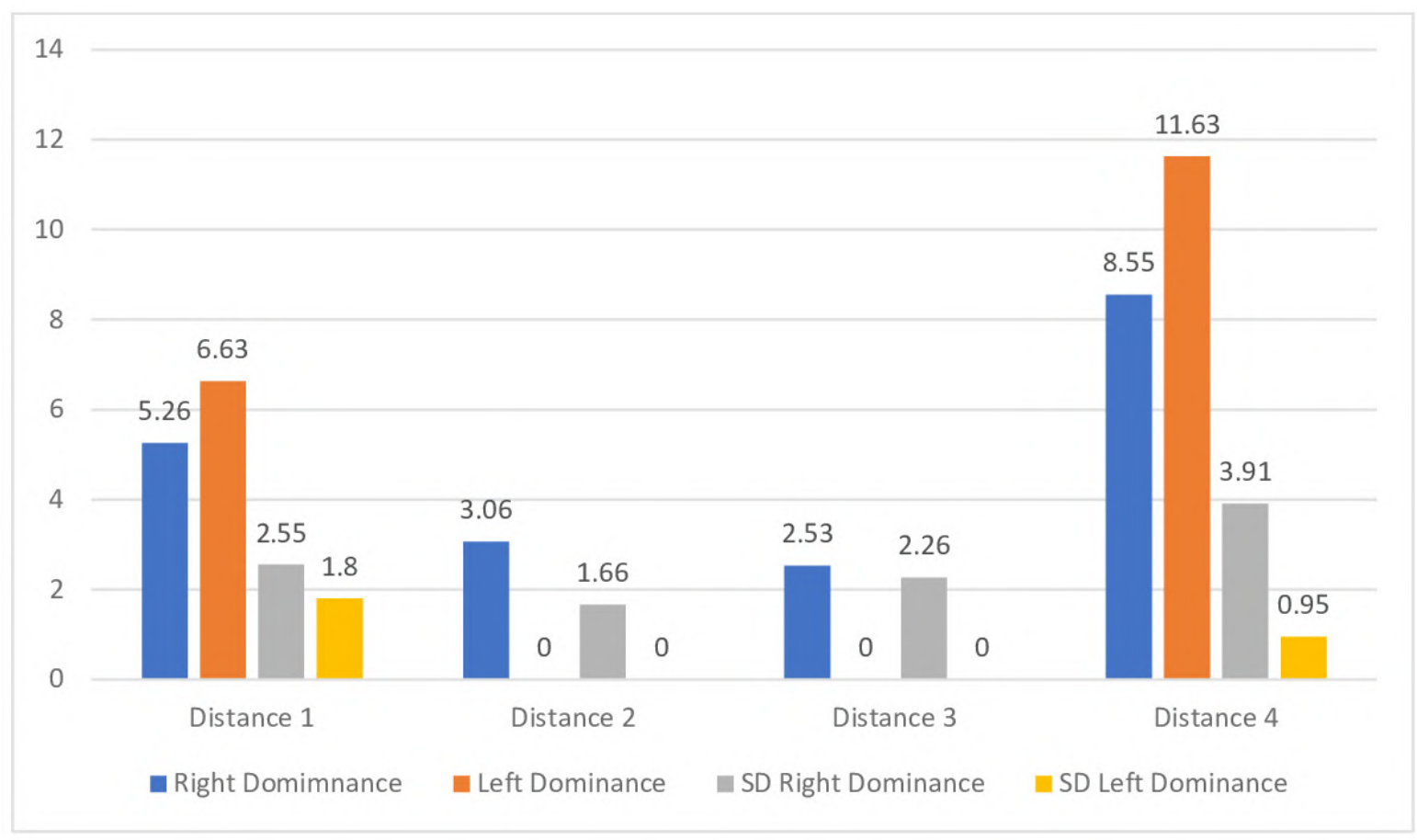

Fig. 4.- Mean distance (in millimeters and standard deviation) between the tricuspid annulus and right coronary artery (RCA), and coronary sinus. Distance 1: distance of the middle third of anterosuperior leaflet to RCA. Distance 2: distance of the anterior-inferior commissure to RCA. Distance 3: distance of the middle third of inferior leaflet to RCA. Distance 4: distance of the middle third of septal leaflet to CS. 
Table 2. Distance comparison between hearts with right and left dominance $(n=35)$.

\begin{tabular}{|l|l|l|l|}
\hline & Right (n=31) & Left (n=4) & p \\
\hline \multirow{2}{*}{ Distance 1 (mm)(SD) } & $5.26(2.55)$ & $6.62(1.80)$ & 0.213 \\
\hline \multirow{2}{*}{ Distance 4 (mm)(SD) } & 6.62 & 1.80 & \\
\hline & $8.55(3.91)$ & $11.62(0.95)$ & 0.064 \\
\hline & 11.62 & .95 & \\
\hline
\end{tabular}

When the heart has a left dominance, the RCA is smaller because it supplies a smaller proportion of myocardial tissue and has a shorter course. In our study, $86.1 \%$ of dissected hearts presented right dominance, $11.1 \%$ left dominance and $2.8 \%$ co-dominance, which were similar to other series (Angelini et al., 2002; Knaapen et al., 2013). We found that when there is left dominance, the RCA ends early and therefore has no relationship to the inferior leaflet.

Dahou et al. (2019) describes that the distance of the RCA at the proximal level is relatively distant from the tricuspid annulus, and gradually approaches the endocardial surface, acquiring at a lower level a distance of less than $3 \mathrm{~mm}$. Sellke and Ruel (2019) mentions that the RCA runs through the $\mathrm{AV}$ groove from the anterior to the posterior annulus, and may be injured by deep stitches at the level of the annulus.

Data derived from previous anatomical studies and evaluations performed with computed tomography (CT) are very similar to our results. Buzzatti et al. (2018), using 44 normal human hearts, reported that the RCA had an average

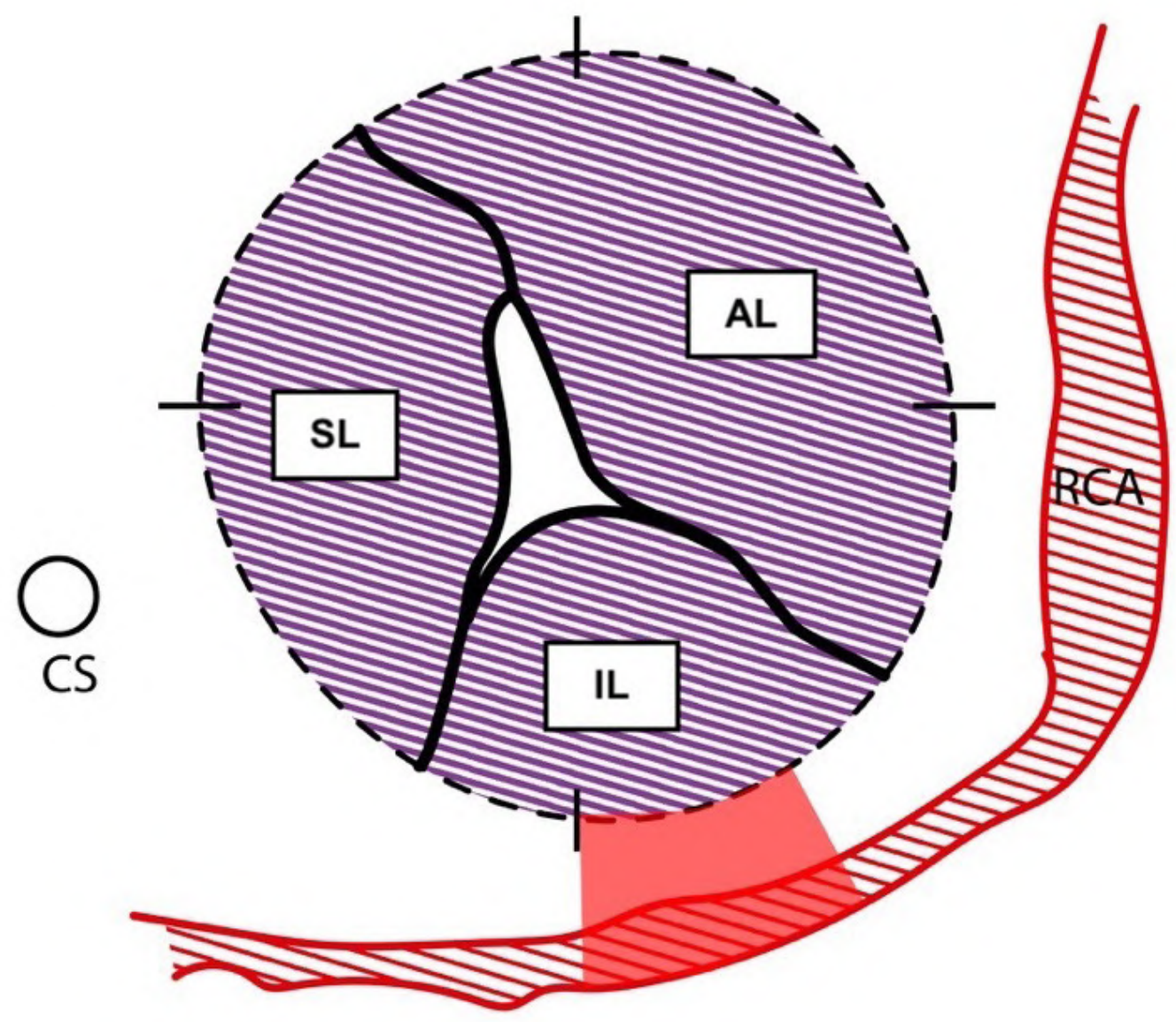

Fig. 5.- Schematic representation of the tricuspid valve of (atrial view) in relation with the right coronary artery, and the coronary sinus. Clockwise system, with the clock being the tricuspid ring, and 0 o'clock half of the anterior annulus. SL: Septal Leaflet. AL: Anterosuperior Leaflet. IL: Inferior Leaflet. CS: Coronary Sinus. RCA: Right Coronary Artery. Red zone, the greatest risk area. 
distance to the tricuspid annulus, which was greatest at the anterosuperior leaflet $(6.8 \mathrm{~mm})$ and shortest at the posterior annulus $(2.1 \mathrm{~mm})$. Van Rosendael et al. (2017) evaluated 250 patients with $\mathrm{CT}$ and reported a distance from the RCA to the anterosuperior leaflet of the tricuspid valve of $8.8 \pm 4.5 \mathrm{~mm}$ and to the inferior leaflet $3.6 \pm 3.4$ $\mathrm{mm}$.

Antunes et al. (2017) describe the management of the tricuspid valve regurgitation. They specify the surgical techniques, and describe that, in annuloplasty techniques, sutures must be placed in the annulus, 1-2 $\mathrm{mm}$ beyond the leaflet hinge line to avoid the adjacent aortic valve and right coronary artery, and the last sutures should be placed in the anteroseptal commissure (right fibrous trigone) and in the middle of the septal annulus to avoid injury to the bundle of His. They describe that in the tricuspid valve replacement accurate prosthesis sizing is essential to prevent distortion of the right coronary artery.

Schofer et al. (2015) report the first human transcatheter tricuspid valve repair with a Mitralign system. They do a plication of the annulus and bicuspidizing the tricuspid valve at the level of the postero-anterior commissure. They consider that the position of the radiofrecuency wire to carry out this procedure must be positioned

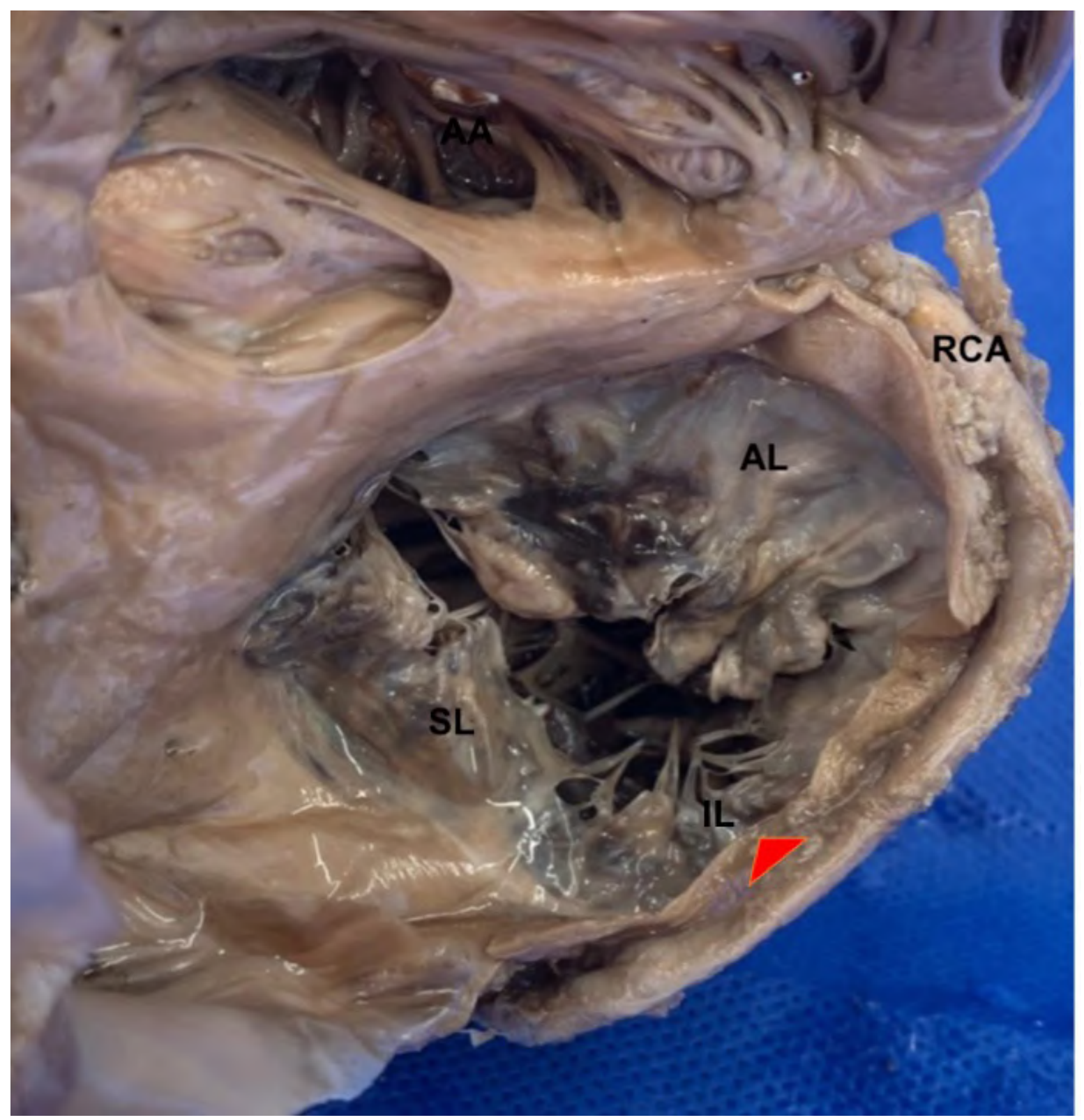

Fig. 6.- Atrial view of the tricuspid valve. Pattern of Right dominance. SL: Septal Leaflet. AL: Anterosuperior Leaflet. IL: Inferior Leaflet. AA: Atrial Appendage. RCA: Right Coronary Artery. Red triangle represents the greatest risk area. 
$2-5 \mathrm{~mm}$ from the base of the leaflet and within the annulus directed toward the right atrium to avoid the right coronary artery perforation.

Taramasso et al. (2019), in the International TriValve Registry, report that 312 patients with severe or greater symptomatic tricuspid regurgitation (TR) underwent transcatheter tricuspid valve intervention (TTVI). Thirty-day mortality was $3.6 \%$, and the mayor adverse events at 30 days were $10.3 \%$, including 2 acute myocardial infarctions requiring right coronary artery stenting (0.7\%). They do not specify whether this was because of compromise or distortion of the right coronary artery.

Iatrogenic damage to the RCA is a rare complication that has serious consequences if not diagnosed and treated early. RCA may be damaged directly during surgery when placing sutures in the tricuspid annulus or indirectly by tightening the tissues located in its closeness. In patients with right coronary dominance, RCA lesions are more frequent at the mid-distal level (Gotor et al., 2018). As we have shown, it is at this point where the artery has its closest relationship with the annulus.

Díez-Villanueva et al. (2014) reviewed their experience regarding direct injury to the RCA related to TV repair in patients with functional TR. Between 2005 and 2012, 499 patients underwent TV surgery, and repair techniques were performed in 450. Direct injury to the RCA complicated 4 of those 450 repair operations. All the patients had critical or sub-occlusive stenosis at the level of the mid or distal portions of the RCA. Díez-Villanueva et al. (2014) comment that the distance between the RCA and the endocardium is particularly small in those areas closest to the tricuspid annulus, especially in the cavotricuspid isthmus in the lower right atrium, with a distance less than $5 \mathrm{~mm}$ in over $80 \%$ of patients. They define a danger zone at the level of the anteroposterior commissure, and risk of RCA occlusion may be minimized by using semirigid rings, applying fewer sutures along the posterior annulus, and avoiding applying the stitches to the atrial wall.

The topography of the iatrogenic damage of the RCA is concordant with our results, in which the shortest distance of the RCA to the annulus is in the posterior annulus.

We did not find any reference regarding injury to the coronary sinus during interventional procedures on the TV (Taramasso et al., 2019). Nonetheless, there are few patients in whom TV devices have been implanted percutaneously, which could explain the scarcity of this report. According to our data, the distance between the TV annulus and the CS is quite safe in hearts with left dominance. In hearts with right dominance, this distance is shorter and therefore might represent an issue to consider during $\mathrm{TV}$ intervention planning.

\section{Limitations}

Measurementswereperformedonformaldehyde fixed hearts, which dehydrates the tissues and can determine alterations in the measurements with respect to fresh or living tissues. We must also consider that the measurements taken were analyzed only in the transversal plane, with no measurements of the ring being made to the RCA in the vertical plane. We were not able to identify the sex of each of the samples (cadaveric samples are not identified), and therefore our data do not allow to consider differences between males and females.

\section{CONCLUSIONS}

Anatomic relationships of the TV annulus with the RCA and CS are important in order to avoid its injury during interventional procedures. The highest risk area of injuring the RCA corresponds to the posterior annulus. TV annulus in hearts with left dominance have a safer distance to the RCA and CS and therefore may present a lower risk of RCA involvement in surgical and endovascular procedures. The anatomical knowledge of the tricuspid valve and its relationships are essential to reduce complications during surgical and endovascular procedures.

\section{ACKNOWLEDGEMENTS}

The authors express special recognition to all who in life decide to donate their body to our faculty, for teaching and research of Anatomy. 


\section{REFERENCES}

ANGELINI P, VELASCO JA, FLAMM S (2002) Coronary anomalies: incidence, pathophysiology, and clinical relevance. Circulation, 105: 2449-2454.

ANTUNES MJ, RODRÍGUEZ-PALOMARES J, PRENDERGAST B, DE BONIS M, ROSENHEK R, AL-ATTAR N, BARILI F, CASSELMAN F, FOLLIGUET T, IUNG B, LANCELLOTTI P, MUNERETTO C, OBADIA JF, PIERARD L, SUWALSKI P, ZAMORANO P (2017) Management of tricuspid valve regurgitation: Position statement of the European Society of Cardiology Working Groups of Cardiovascular Surgery and Valvular Heart Disease. Eur J Cardiothorac Surg, 52(6): 1022-1030.

BUZZATTI N, DE BONIS M, MOAT N (2018) Anatomy of the tricuspid valve, pathophysiology of functional tricuspid regurgitation, and implications for percutaneous therapies. Interv Cardiol Clin, 7: 1-11.

CAMPELO F, LAIREZ O, CARRIÉ D (2017) Tratamientos percutáneos de la valvulopatía tricuspídea: una nueva esperanza para la válvula olvidada. Rev Esp Cardiol, 70(10): 856-866.

DAHOU A, LEVIN D, REISMAN M, HAHN RT (2019) Anatomy and physiology of the tricuspid valve. JACC Cardiovas Imaging, 12: 458-468.

DÍEZ-VILLANUEVA P, GUTIÉRREZ-IBANES E, CUERPO-CABALLERO G, SANZ-RUIZ R, ABEYTUA M, SORIANO J, Sarnago F, Elízaga J, González-Pinto A, Fernández-Avilés F (2014) Direct injury to right coronary artery in patients undergoing tricuspid annuloplasty. Ann Thorac Surg, 97: 1300-1305.

GOTOR CA, CENTENO JE, PÉREZ E, LÓPEZ MJ, CORTINA JM (2018) Iatrogenic occlusion of the right coronary artery during tricuspid valve replacement. Rev Colomb Cardiol, 26: 296-299.

KNAAPEN M, KOCH AH, KOCH C, KOCH KT, LI X, VAN ROOIJ PC, TIJSSEN JGP, PETERS RJ, VAN DER WAL AC, DAMMAN P, DE WINTER RJ (2013) Prevalence of left and balanced coronary arterial dominance decreases with increasing age of patients at autopsy. A postmortem coronary angiograms study. Cardiovas Pathol, 22(1): 49-53.

SCHOFER J, BIJUKLIC K, TIBURTIUS C, HANSEN L, GRPPTHUIS A, HAHN R (2015) First-human transcatheter tricuspid valve repair in a patient with severely regurgitant tricuspid valve. J Am Coll Cardiol, 65: 1190-1195.

SELLKE F, RUEL M (2019) Tricuspid valve operation. In: Elmistekawy E, Mesana TG (eds). Atlas of Cardiac Surgical techniques, $2^{\text {nd }}$ edition. Russell Gabbedy, Philadelphia, USA, pp 384-405.

TARAMASSO M, ALESSANDRINI H, LATIB A, ASAMI M, ATTINGERTOLLER A, BIASCO L, et al. (2019) Outcomes after current transcatheter tricuspid valve intervention. Mid-term results from the international trivalve registry. JACC: Cardiovascular Intervention, 12(2): 155-165. doi: 10.1016/j.jcin.2018.10.022.

VAN ROSENDAEL PJ, KAMPERIDIS V, KONG WK, VAN ROSENDAEL AR, VAN DER KLEY F, AJMONE N, DELGADO V, BAX JJ (2017) Computed tomography for planning transcatheter tricuspid valve therapy. Eur Heart J, 38(9): 665-674.

VASSILEVA CM, SHABOSKY J, BOLEY T, MARKWELL S, HAZELRIGG S (2012) Tricuspid valve surgery: the past 10 years from the Nationwide Inpatient Sample (NIS) database. J Thorac Cardiovasc Surg, 143(5): 10431049. 